\section{SMART HARD HAT}

Petri Kähärä, Aleksi Sallinen, Jonne Holmén. Gonsul Ltd, Finland

10.1136/injuryprev-2016-042156.645

Background Smart Hard Hat is an innovation created by Gonsul Ltd. The innovation was created in Finnish Transport Agency's (FTA) innovation competition to improve work safety on infrastructure. Innovation was awarded with $3^{\text {rd }}$ place and nomination in high innovativeness among hundreds of competitors.

Methods Smart Hard Hat gathers data from its environment and the user. Smart Hard Hat includes technology in hard hat in a way that makes it possible to act into emergency situations. This kind of technology is collection of sensors like acceleration and speed, GPS, wireless internet and cloud service. Smart Hard Hat is passive, wearable technology that leaves workers hands free. The supervisors need mobile access to data base to be able to handle the information gathered.

Results The proof-of-concept about Smart Hard Hat is about to begin soon. Only hypothesis about the results can be given. A suggestion is that Smart Hard Hat declines the amount of critical accidents in work. This happens in two ways. Firstly, the data that is gathered may be used efficiently in a way that improves safeness. A dangerous patterns may be found that connects different kind of situations and environmental aspects together. Secondly, the workers may receive fast help immediately after the accident has happened. Smart Hard Hat can recognise when thresholds dangerous for life are exceeded and send a message to supervisor.

Conclusions By taking Smart Hard Hat widely into use it may significantly decrease the amount of fatal accidents in work. Also non-fatal accidents in work can be radically decreased. Benefits are gained by the employer, employee and the society multidimensionally.

\section{Child and Adolescent Safety}

\section{Post Tue 2.4}

\section{INCOME INEQUALITY, DEVELOPMENT AND CHILD INJURIES: AN ECOLOGICAL STUDY IN LOW- AND MIDDLE INCOME COUNTRIES}

${ }^{1}$ Mathilde Sengoelge, ${ }^{2}$ Nukhba Zia, ${ }^{1}$ Marie Hasselberg. ${ }^{1}$ Karolinska Institutet, Sweden; ${ }^{2} J o h n s$ Hopkins International Injury Research Unit, Department of International Health, Johns Hopkins Bloomberg School of Public Health, USA

\subsection{6/injuryprev-2016-042156.646}

Background The relationship between lower economic level and high injury rates in children is well established, but less is known about how development measures shape child injury inequalities, especially in low- and middle-income countries. The aim of this study is to assess the strength of the relationship between child injury mortality rates and existing country level development measures in Sub-Saharan Africa and South Asia, the two regions with the highest child injury mortality rates globay.

Methods This was an ecological, cross-sectional country level study in 54 countries comprising the Sub-Saharan Africa and South Asia region participating in the Global Burden of Disease (GBD) project. The outcome measure was injury mortality rates per 100,000 for the 1-14 age group calculated from the GBD 2013, 2000, 1990. Country level measures chosen to reflect the core domains of development relevant to child well-being (economy/socioeconomic status, governance and human rights) were extracted from the World Bank Open Database, the Institute for Economics and Peace and the Economist Intelligence Unit. Pearson's correlation coefficient was used to examine the association between development measures and all injuries/unintentional/ intentional child mortality rates for both regions combined in 2013. Injury mortality rates were then presented for each region in 1990, 2000 and 2013.

Results Development variables that showed significant correlation with unintentional injury mortality included: Democracy Index, improved water source for the rural population, infant mortality rate, under-5 mortality rate, maternal mortality rate, life expectancy at birth and private prepaid plans. None correlated with intentional injuries. There was a decrease in all injury and unintentional mortality rates for both regions from 1990 to 2013; intentional rates increased 1990 to 2000 and are now (2013) decreasing again.

Conclusion Injury mortality rates declined overall in both regions from 1990 to 2013 but within and between regional differences exist and must be addressed in order to reduce child injury inequality on a global scale; further research is needed to improve our understanding of how development affects these rates.

\section{RESEARCH ON THE PROMOTING CHILDREN'S KNOWLEDGE OF INJURY BY CHESS GAMES}

${ }^{1}$ Yang Ya-ming, ${ }^{2}$ Gao xing, ${ }^{3}$ Cui Meng-jing, ${ }^{3}$ Cheng Yu, ${ }^{3}$ Li Yang, ${ }^{3}$ Li Zhen, ${ }^{3}$ Zhang Xujun, ${ }^{1}$ Zhu Jun. ${ }^{1}$ Yixing Centrefor Disease Control and Prevention, China; ${ }^{2}$ The National Centrefor Chronic and Noncommunicable Disease Control and Prevention, China; ${ }^{3}$ College of Public Health, Southeast University, China

\subsection{6/injuryprev-2016-042156.647}

Background Injury is the most important factor in the threat to children's health and playing a game is children's favourite method of participation. We try to promote child injury prevention and improve mental health through the games.

Methods The chess game is designed and made by the National Centre for Disease Control and Prevention. Survey and intervention were conducted in 666 primary school students (Grade 3 to Grade 5) in Yixing City, Jiangsu Province from September 2014 to February 2015. Instrument was the Related questionnaire: Knowledge of injury prevention questionnaire and satisfaction questionnaire and the Mental health promoting chess: a 2-6 player game.

Methods

- Students played the game with the help of teacher, and then played the game by themselves.

- Two researches were conducted in the knowledge of injury before and after half a year. Finally, there was a satisfaction survey.

Results After the intervention, the children's injury prevention knowledge accuracy was higher than before. The difference was statistically significant $(\mathrm{P}<0.05)$. Children who liked the chess were more than those who didn't. And children who wanted the chess were more than those who didn't if there were similar chess games. Girls prefer the chess than boys and there is no difference between grade groups.

Conclusion Chess games have a certain effect. It is welcomed and worthy of popularising. 